\title{
Fac vs Mer Selection in Octahedral Complexes of the $N$-Benzyl- Substituted Triazolylpyridine Diad with Labile Metal Ions (Zinc(II), Iron(II), and Nickel(II))
}

\author{
Mona AshrafKhorasani, Nan Wu, Olivier Fleischel, Gabriele Schatte, and Anne Petitjean*(0) \\ Department of Chemistry, Queen's University, 90 Bader Lane, Kingston, ON K7L3N6, Canada
}

Supporting Information

\begin{abstract}
Pseudo-octahedral complexes built on chelating ligands offer valuable isomeric properties such as the formation of fac vs mer isomers, and $\Lambda$ vs $\Delta$ enantiomers. This article discusses factors guiding the fac vs mer selection of complexes built from the triazolyl-pyridine platform bearing a benzyl substituent, in conjunction with labile metal ions such as zinc(II), iron(II), and nickel(II). Critical parameters that are explored include the geometrical flexibility of the individual metal ion, and the nature of the counteranion. In essence, it was observed that ions which can withstand significant distortions in their first coordination sphere, such as zinc(II), generally prefer forming the mer isomer irrespective of the counteranion, whereas ions with more restricted geometry, such as iron(II), are directed either to a fac arrangement by small, tetrahedral anions such as

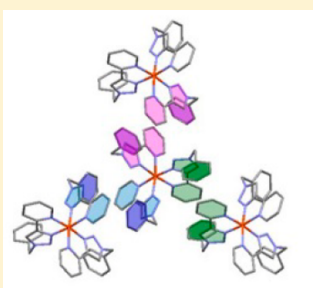

Fac ('dimerization boxes')

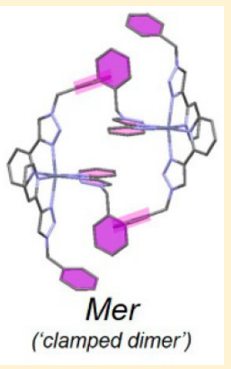

('clamped dimer') tetrafluoroborate or perchlorate or to a mer organization by counteranions of lower symmetry, such as triflate. The molecular interactions operating the selection are discussed. Interestingly, such iron(II) complexes are prime candidates for spin crossover behavior; hence, understanding their isomeric selection may assist in guiding the design of solid-state magnetic materials.
\end{abstract}

\section{INTRODUCTION}

Due to its facile synthesis, the triazolylpyridine diad has attracted significant attention in the elaboration of architectures relying on transition metals of octahedral geometry, where it plays the role of a $2,2^{\prime}$-bipyridine substitute, albeit with its unique binding strength, ${ }^{1-6}$ and optical, ${ }^{7-11}$ magnetic, ${ }^{4,11-14}$ and electrochemical $^{15-17}$ properties. As a result, a plethora of self-assembled architectures using this diad as metallo-connectors has emerged in the last 10 years. ${ }^{18-25}$ Ligands of interest involve multifunctional units where the triazolylpyridine diads are bridged by spacers connected through the $\mathrm{N} 1$ of the triazole, and labile metal ions that promote thermodynamic equilibration. As part of this process, the orientation of ligands around the first metal ion is influenced by the thermodynamic benefit of incorporating a second ion along the strand. For instance, the selfassembly of a dinuclear helicate such as that represented in Figure $1 \mathrm{~b}$, resulting from a 2:3 mixture of $\left[\mathrm{Fe}\left(\mathrm{H}_{2} \mathrm{O}\right)_{6}\right]\left(\mathrm{BF}_{4}\right)_{2}$ and ligand L2, requires that each coordination unit adopt a $\mathrm{fac}$ orientation. The observation that a $1: 3$ mixture of $\left[\mathrm{Fe}\left(\mathrm{H}_{2} \mathrm{O}\right)_{6}\right]$ $\left(\mathrm{BF}_{4}\right)_{2}$ with ligand $\mathbf{L 1}$ also crystallizes exclusively as a $\mathrm{fac}$ complex $^{18}$ begs the question of how predictable/systematic the selection of the fac isomer is. In other words, what are the selection rules, if any, behind the solid-state formation of the fac vs mer mononuclear complexes of labile metal ions? Labile ions are of particular interest, as equilibration between the fac and mer isomers facilitates selection (inert ions, which are subject to being kinetically trapped in one or several form(s) in the course of complex formation, are not amenable to this analysis $^{25}$ ).

\section{GAS AND SOLUTION STATE DISCUSSION}

Before dissecting the solid-state assembly, a brief discussion of the possible geometrical biases in the gas and solution phases is worthwhile. As reported earlier, ${ }^{4}$ DFT calculations on the low-spin iron(II) complex ${ }^{26,27}$ of the N1-methyl-substituted triazolylpyridine model indicate that the energy levels of the $\mathrm{fac}$ and mer isomers are within $0.1 \mathrm{kcal} / \mathrm{mol}$ of each other, ${ }^{42}$ suggesting no bias of the triazole-pyridine diad toward one structure vs the other in the gas phase. In solution in acetonitrile (and acetonitrile/chloroform mixtures), the $\left[\mathrm{Fe}(\mathbf{L 1})_{3}\right]^{2+}$ complex displays broad ${ }^{1} \mathrm{H}$ NMR signals at room temperature (Figure 2a), contrary to the better resolved dinuclear helicate signature obtained with bifunctional ligands under the same conditions, ${ }^{4}$ indicating an enhanced dynamic equilibrium in the mononuclear complex, which could be dominated by one of two effects: (i) Dissociation of the 3:1 ligand-to-ion complex, or (ii) isomerization between the mer and $f a c$ isomers. The significant downfield shift of the triazole proton ( $t$, see Figure 1a for numbering) compared to the free ligand confirms that the triazole unit is bound (Figure 2a). Most importantly, the pyridine H6 proton shows a remarkable upfield shift in the presence of $\mathrm{Fe}(\mathrm{II})$. Indeed, in the free ligand, $\mathrm{H} 6$ typically appears at high chemical shift ( $8.54 \mathrm{ppm}$ in $\mathbf{L} \mathbf{1}$ in $1: 1 \mathrm{CDCl}_{3} / \mathrm{CD}_{3} \mathrm{CN}$ ) due to the inductive effect of the ortho nitrogen on the pyridine ring.

Received: October 26, 2017

Revised: December 4, 2017

Published: February 8, 2018 


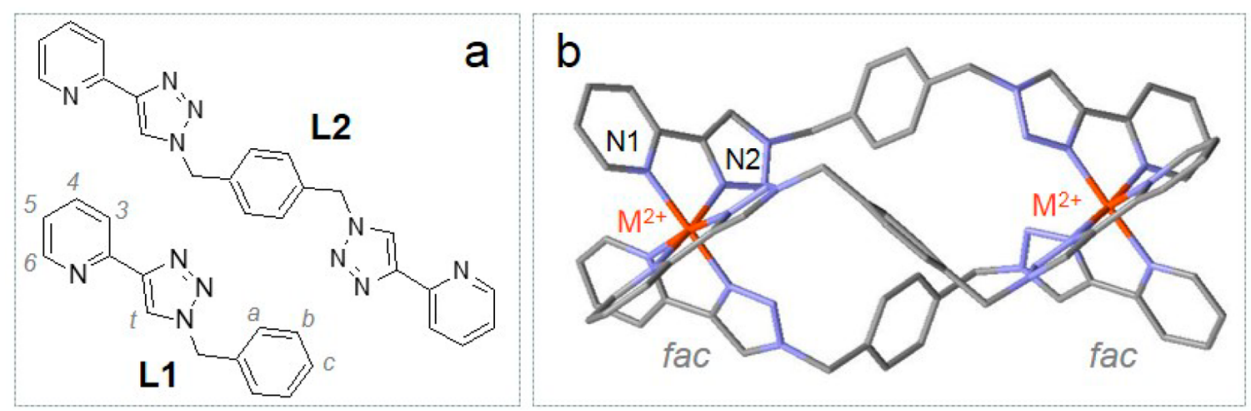

Figure 1. (a) Chemical structure of monofunctional (L1) and bifunctional (L2) chelating ligands (numbered positions on $\mathbf{L 1}$ are indicated for ${ }^{1} \mathrm{H}$ NMR assignment purposes). (b) Solid-state structure of dinuclear complexes based of ligand $\mathbf{L} \mathbf{2}$ (tetrafluoroborate counteranions, hydrogen atoms, and solvents omitted for clarity). Selected distances: $\mathrm{M}=\mathrm{Ni}(\mathrm{II}), \mathrm{Ni} \cdots \mathrm{N} 12.102(3) \AA ̊ \mathrm{Ni} \cdots \mathrm{N} 22.057(2) \AA$; $\mathrm{M}=\mathrm{Fe}(\mathrm{II}), \mathrm{Fe} \cdots \mathrm{N} 11.998(2) \AA, \mathrm{Fe} \cdots \mathrm{N} 2$ $1.939(2) \AA ̊$.

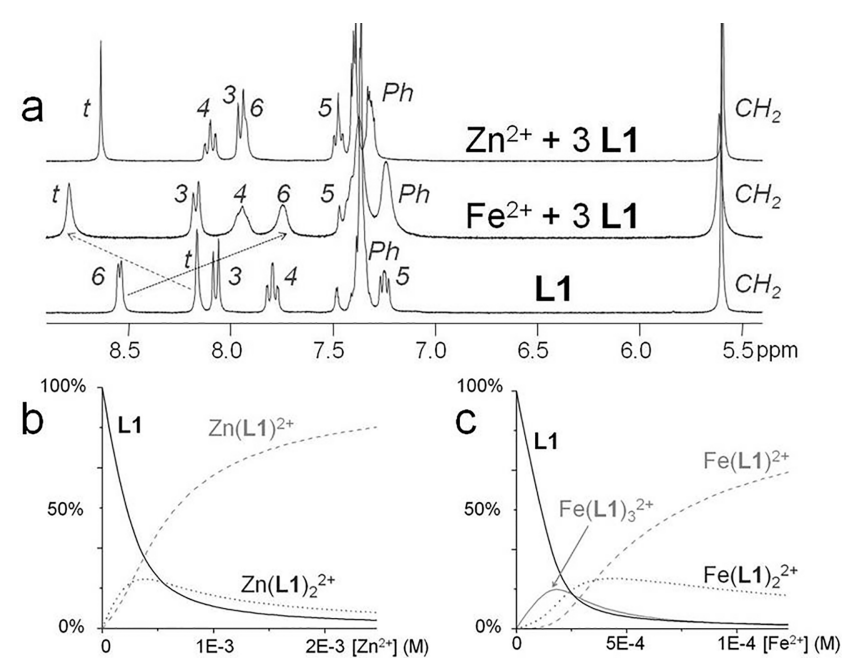

Figure 2. (a) ${ }^{1} \mathrm{H}$ NMR spectra of $1: 3$ mixtures of $\mathrm{Zn}(\mathrm{OTf})_{2} / \mathbf{L} \mathbf{1}$, $\left[\mathrm{Fe}\left(\mathrm{H}_{2} \mathrm{O}\right)_{6}\right]\left(\mathrm{BF}_{4}\right)_{2} / \mathbf{L 1}$, and free ligand $\mathbf{L 1}$ in $1: 1 \mathrm{CDCl}_{3} / \mathrm{CD}_{3} \mathrm{CN}$ $\left(\left[\mathrm{M}(\mathbf{L} \mathbf{1})_{3}\right] \sim 10 \mathrm{mM},[\mathbf{L 1}] \sim 30 \mathrm{mM}, 300 \mathrm{MHz}\right.$, referenced using the residual acetonitrile signal). Assignments were based on COSY signals and coupling constants (see Figure 1 for numbering). Species distribution for complexes of $\mathbf{L 1}$ with (b) $\mathrm{Zn}(\mathrm{OTf})_{2}$ in $\mathrm{CH}_{3} \mathrm{OH}$, $[\mathbf{L 1}] \sim 5 \times 10^{-4} \mathrm{M}$, and (c) $\left[\mathrm{Fe}\left(\mathrm{H}_{2} \mathrm{O}\right)_{6}\right]\left(\mathrm{BF}_{4}\right)_{2}$ in $\mathrm{CH}_{3} \mathrm{CN}$, [L1] $\sim 5$ $\times 10^{-5} \mathrm{M}$. Graphs were produced using association constants determined by UV-vis titrations provided in the Supporting Information $\left(\mathrm{Zn}^{2+}: \log \beta_{11}=4.12 \pm 0.03, \log \beta_{21}=7.70 \pm 0.07\right.$; $\left.\mathrm{Fe}^{2+}: \log \beta_{11}=5.65 \pm 0.05, \log \beta_{21}=10.9 \pm 0.1, \log \beta_{31}=15.7 \pm 0.1\right)$.

This effect is generally enhanced upon 1:1 metal-to-ligand coordination due to the increased electron-withdrawing effect upon ion binding. However, in the 1:3 metal-to-ligand pseudooctahedral complexes involving aromatic heterocyclic chelating ligands, the $\mathrm{H} 6$ proton of one chelate is strongly shielded by the electronic cloud of the other two chelates, resulting in a significantly lower chemical shift for $\mathrm{H} 6(\delta(\mathrm{H} 6)$ is 7.7 and $7.9 \mathrm{ppm}$ in the iron(II) and zinc(II) complexes with L1, respectively). As a result, ${ }^{1} \mathrm{H}$ NMR spectroscopy suggests that both the zinc and iron complexes are mostly pseudo-octahedral species, incorporating three pyridyl-triazole chelates, at $10^{-3}-10^{-2} \mathrm{M}$ concentrations. Binding constant determination by $\mathrm{UV}-$ vis titration at sub$\mathrm{mM}$ concentrations (Figure $2 \mathrm{~b}$ and the Supporting Information) confirms that the iron complex should be fully saturated at concentrations used for ${ }^{1} \mathrm{H}$ NMR analysis. Hence the observed ${ }^{1} \mathrm{H}$ NMR dynamic behavior likely primarily stems from intermediate-to-fast exchange between the mer and fac complexes. In their study of the same $\left[\mathrm{Fe}(\mathbf{L} \mathbf{1})_{3}\right]^{2+}$ complex, Crowley and co-workers also confirmed the coexistence of equilibrating $\mathrm{fac}$ and mer isomers which reveal their NMR signature at $208 \mathrm{~K}$, as a statistical mixture. ${ }^{19}$

\section{SOLID-STATE ANALYSIS}

Contrary to the solution studies above, crystallization of $1: 3$ mixtures of $\left[\mathrm{Fe}\left(\mathrm{H}_{2} \mathrm{O}\right)_{6}\right]\left(\mathrm{BF}_{4}\right)_{2}$ and $\mathbf{~} \mathbf{1}$ by diethyl ether vapor diffusion into a concentrated solution in acetonitrile consistently yields the $f a c$ isomer as the sole product (Figure $3 c$ ), in a racemic mixture of $\Lambda$ and $\Delta$ complexes. Several interactions contribute to the packing of the fac isomer in the solid state. Each planar coordinated diad is engaged in a "dimerization box" resulting from $\pi-\pi$ stacking of its polarized surface (planeplane distance: $3.36 \AA$, in light purple, Figure 3a) complemented by edge-to-face interactions between the edge of the pyridine with the phenyl ring of the neighboring benzyl substituent (light pink, Figure 3a). In addition to these contacts between organic fragments, the dimerization box is reinforced by weak H-bonding between the fluorine atoms of the tetrafluoroborates and the weakly acidic $\mathrm{CH}$ bonds, polarized by the coordination of the heterocycles (dashed lines, Figure 3a), at the edge of the dimerization box. The tetrahedral shape of the tetrafluoroborate anion allows it to make contact with several of these hydrogen atoms. The most significant such weak interaction involves fluorine F2 and the triazole hydrogen from one diad, a common partner in molecular recognition $(\mathrm{H} 1 \cdots \mathrm{F} 2$, Figure 3a; Table 1). ${ }^{28-35}$ The same tetrafluoroborate extends a second hydrogen bond to the other, stacked, diad, through the pyridine "ortho" hydrogen (F1‥H7, Figure 3a). Finally, very weak contacts are made between fluorine $\mathrm{F} 4$ of the same tetrafluoroborate and the benzylic group $\left(\mathrm{CH}_{2}\right.$ and $\mathrm{Ph}$ group; Figure 3a). Overall, the dimerization box benefits not only from the aromatic interactions of the organic fragments but also from multiple hydrogen bonds provided by the counteranion of appropriate tetrahedral shape. Such dimerization box is implemented on each of the three chelates around the metal ion (Figure 3b), leading to a tight $3 \mathrm{D}$ network. Such maximization of $\pi-\pi$ stacking around the three diads is a common feature with higher order, dinuclear architectures such as iron(II) helicates based on the bisbenzyl-like xylyl spacer. ${ }^{18}$

Not surprisingly, replacing the tetrafluoroborate with an anion of similar symmetry and bond polarization such as a perchlorate gives rise to an essentially isomorphous structure, as seen in the solid state of $1: 3$ mixtures of $\left[\mathrm{Fe}\left(\mathrm{H}_{2} \mathrm{O}\right)_{6}\right]\left(\mathrm{ClO}_{4}\right)_{2}$ and $\mathbf{L 1}$. As apparent from Figure $3 \mathrm{c}$, the solid-state structure of the perchlorate complex (purple) is superimposable to the tetrafluoroborate analogue (pink), including the orientation of the benzyl substituents (edge-to-face contribution) and that of the anion 


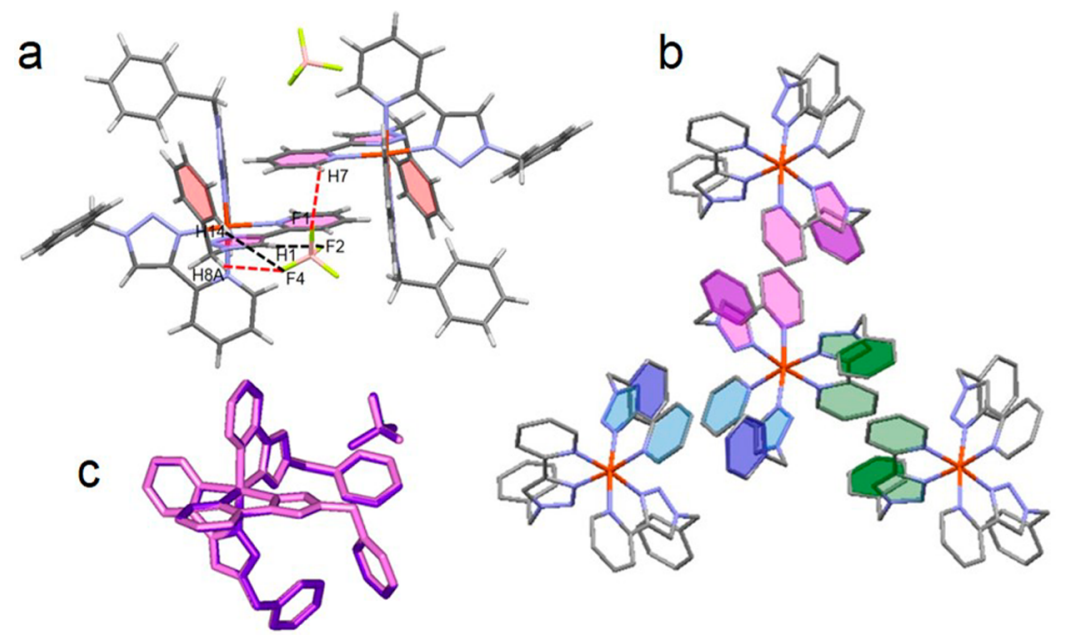

Figure 3. Solid-state structure of $\left[\mathrm{Fe}(\mathbf{L 1})_{3}\right]\left(\mathrm{BF}_{4}\right)_{2}$. (a) Dimerization box held by $\pi-\pi$ stacking of the triazolylpyridine diads (in light purple), edgeto-face interactions of the diads with the phenyl rings (pink), and $\mathrm{H}$-bonding to the $\mathrm{BF}_{4}$ anion (dashed lines). (b) View of the three dimerization boxes around one complex (each dimerization box is color-coded for clarity, in shades of pink, blue, and green; hydrogen atoms and counteranions are omitted for clarity). (c) Overlay of the $\left[\mathrm{Fe}(\mathbf{L 1})_{3}\right]\left(\mathrm{BF}_{4}\right)_{2}$ (pink) and $\left[\mathrm{Fe}(\mathbf{L 1})_{3}\right]\left(\mathrm{ClO}_{4}\right)_{2}$ (purple) solid-state structures (hydrogen atoms are omitted for clarity).

Table 1. Distances and Angles Involved in Hydrogen-Bonding within Self-Assembled $\left[\mathrm{Fe}(\mathrm{L1})_{3}\right]\left(\mathrm{BF}_{4}\right)_{2}$

$\begin{array}{lllll} & \mathrm{H}^{b} \cdots \mathrm{F} 2 & \mathrm{H} 7^{b} \cdots \mathrm{F} 1 & \mathrm{H}_{8} \mathrm{~A}^{c} \cdots \mathrm{F} 4 & \mathrm{H} 14^{b} \cdots \mathrm{F} 4 \\ \mathrm{H} \cdots \mathrm{A} \text { distance }(\AA)^{a} & 2.16 & 2.57 & 2.53 & 2.67 \\ \mathrm{D} \cdots \mathrm{A} \text { distance }(\AA) & 3.103(5) & 3.184(7) & 3.389(6) & 3.420(6) \\ \mathrm{D}-\mathrm{H} \cdots \mathrm{A} \text { angle }(\mathrm{deg})^{a} & 175.5 & 122.4 & 144.6 & 137.7\end{array}$

${ }^{a} \mathrm{H}$ atoms fixed at geometrically idealized positions. ${ }^{b} \mathrm{D}-\mathrm{H}$ distance set to $0.95 \AA \AA$ on $\mathrm{sp}^{2}$ carbon ${ }^{c} \mathrm{D}-\mathrm{H}$ distance set to $0.99 \AA \AA$ on sp ${ }^{3}$ carbon.

(H-bonding), attesting to the importance of the interactions of the ${ }^{\delta-} \mathrm{F} /{ }^{\delta-} \mathrm{O}$ of the anion with $\mathrm{C}-\mathrm{H}$ units from the organic framework.

The same tetrafluoroborate and perchlorate counteranions yield two new isostructural zinc complexes, but select the mer isomer instead. Rather than self-assembling into three dimerization boxes all around the octahedral complex as in the fac isomer above, the mer zinc isomer facilitates the collapse of all the organic fragments along one interface, in a "clamp-like" arrangement of the two enantiomers (Figure 4a). Such selfassembly relies on the following weak interactions:

(i) $\pi-\pi$ stacking of head-to-tail diads takes place in the same manner as in the fac iron(II) complexes described above (distance between pyridine planes: $3.29 \AA$ ). However, in the mer complex, the phenyl rings do not close the dimerization box up, but one on each unit flips up/down to engage further in face-to-face $\pi-\pi$ stacking with the stacked diads on either side (phenyl rings A, Figure 4a). Additional $\pi-\pi$ stacking between the "lateral" pyridines allows the growth of self-assembled "clamped" dimers into an infinite 1D thread (Supporting Information, Figure S3).

(ii) Each phenyl ring A engages in edge-to-face interactions with a phenyl ring (B) on the partner complex, which offers an additional phenyl ring $(C)$ to cap the whole structure through edge-to-face interactions with B (top phenyl C plane to $\mathrm{CH}$ on phenyl B: $2.74 \AA$ ) .

(iii) The axial arrangement of two triazoles allows the short contact of two triazole nitrogen (N6, Figure 4b) with the weakly acidic "para" pyridine proton (H5, Figure 4b).

(iv) The clamp structure of the organic fragments is reinforced by H-bonding with the fluorine atoms of the tetrafluoroborate anions (Figure 4b). The diad stack is
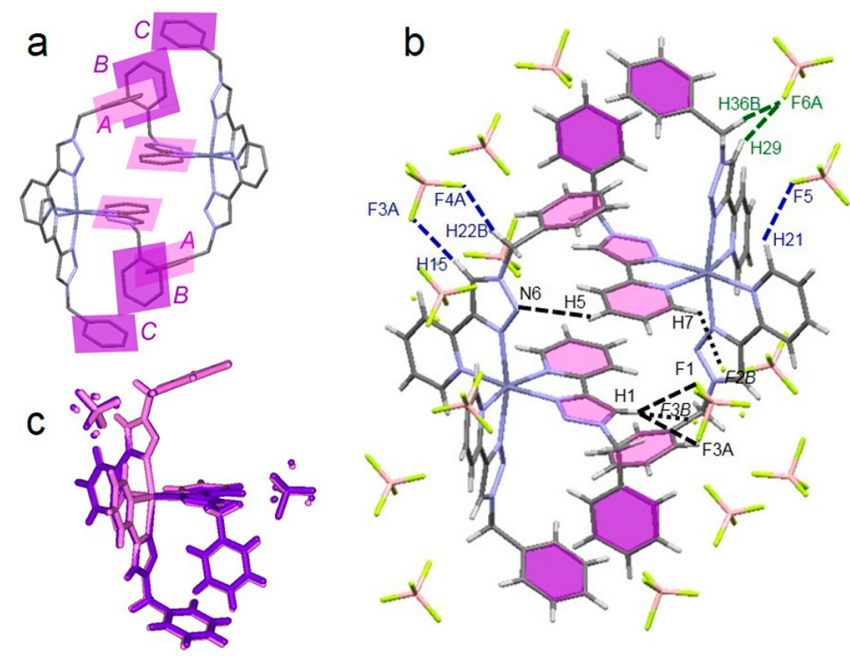

Figure 4. Solid-state structure of $\left[\mathrm{Zn}(\mathrm{L1})_{3}\right]\left(\mathrm{BF}_{4}\right)_{2}$. (a) Self-assembled "clamp" of enantiomers held by $\pi-\pi$ stacking of the triazolylpyridine diads and " $A$ " phenyl rings (pink), and edge-to-face interactions of the phenyl rings ( $\mathrm{A}$ in pink, $\mathrm{B}$ and $\mathrm{C}$ in purple); hydrogen atoms are omitted for clarity. (b) H-bonding to the $\mathrm{BF}_{4}$ anion (dashed lines). (c) Overlay of the $\left[\mathrm{Zn}(\mathbf{L} 1)_{3}\right]\left(\mathrm{BF}_{4}\right)_{2}$ (pink) and $\left[\mathrm{Zn}(\mathbf{L 1})_{3}\right]\left(\mathrm{ClO}_{4}\right)_{2}$ (purple) solid-state structures (hydrogen atoms are omitted for clarity).

consolidated by the contact of F1, F3A, and F3B (the latter belonging to a disordered position) and $\mathrm{H} 1$ on the triazole unit, as well as by the contact of F2B with the "ortho" hydrogen on the pyridine of the diad above (H7, Figure $4 \mathrm{~b}$; Table 2). The capping by phenyl rings at the top and bottom of the assembly is complemented by the hydrogenbonding fork between F6A and the triazole $\mathrm{H} 29$ and 
Table 2. Distances and Angles Involved in Hydrogen-Bonding within Self-Assembled $\left[\mathrm{Zn}(\mathrm{L1})_{3}\right]\left(\mathrm{BF}_{4}\right)_{2}$

\begin{tabular}{|c|c|c|c|c|c|}
\hline & $\mathrm{H} 1^{b} \cdots \mathrm{F} 1$ & $\mathrm{H} 1^{b} \cdots \mathrm{F} 3 \mathrm{~A}$ & $\mathrm{H} 1^{b} \cdots \mathrm{F} 3 \mathrm{~B}$ & $\mathrm{H} 7^{b} \cdots \mathrm{F} 2 \mathrm{~B}$ & $\mathrm{H} 5^{b} \cdots \mathrm{N} 6$ \\
\hline $\mathrm{H} \cdots \mathrm{A}$ distance $(\AA)^{a}$ & 2.36 & 2.48 & 2.59 & 2.60 & 2.72 \\
\hline $\mathrm{D} \cdots \mathrm{A}$ distance $(\AA)$ & $3.219(3)$ & $3.280(4)$ & $3.232(9)$ & $3.287(9)$ & $3.429(3)$ \\
\hline \multirow[t]{2}{*}{$\mathrm{D}-\mathrm{H} \cdots \mathrm{A}$ angle $(\mathrm{deg})^{a}$} & 150.1 & 141.9 & 125.7 & 129.4 & 132.4 \\
\hline & $\mathrm{H} 36 \mathrm{~B}^{c} \cdots \mathrm{F} 6 \mathrm{~A}$ & $\mathrm{H} 29^{b} \cdots \mathrm{F} 6 \mathrm{~A}$ & $\mathrm{H} 15^{b} \cdots \mathrm{F} 3 \mathrm{~A}$ & $\mathrm{H} 22 \mathrm{~B}$ & \\
\hline $\mathrm{H} \cdots \mathrm{A}$ distance $(\AA)^{a}$ & 2.50 & 2.45 & 2.35 & 2.4 & \\
\hline $\mathrm{D} \cdots \mathrm{A}$ distance $(\AA)$ & $3.310(4)$ & $3.113(4)$ & $3.223(4)$ & 3.2 & \\
\hline $\mathrm{D}-\mathrm{H} \cdots \mathrm{A}$ angle $(\mathrm{deg})^{a}$ & 139.0 & 127.2 & 153.3 & 138 & \\
\hline
\end{tabular}

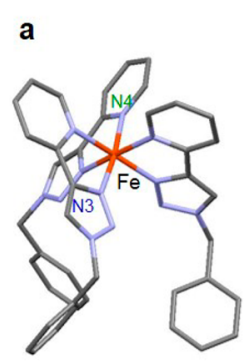

$2 \mathrm{BF}_{4}$

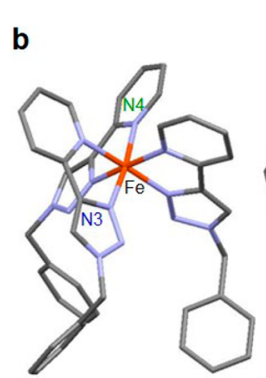

$2 \mathrm{ClO}_{4}^{-}$
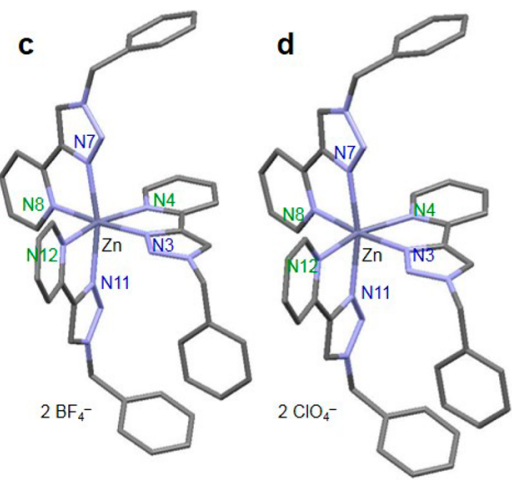

Figure 5. Views of the individual mononuclear complexes aimed at focusing on the bond angles across the metal ions in $\left[\mathrm{Fe}(\mathbf{L 1})_{3}\right](\mathrm{BF})_{2}(\mathrm{a})$, $\left[\mathrm{Fe}(\mathbf{L 1})_{3}\right]\left(\mathrm{ClO}_{4}\right)_{2}(\mathrm{~b}),\left[\mathrm{Zn}(\mathbf{L 1})_{3}\right]\left(\mathrm{BF}_{4}\right)_{2}(\mathrm{c})$, and $\left[\mathrm{Zn}(\mathbf{L 1})_{3}\right]\left(\mathrm{ClO}_{4}\right)_{2}(\mathrm{~d})$ (hydrogen atoms are omitted for clarity; the labels for $\mathrm{N}$ from pyridines are color-coded in green, and the triazole nitrogen labels appear in blue). Quantitative angles and bond lengths may be found in Table 3.

Table 3. Selected Angles (deg) and Bond Lengths (̊̊) around the Metal Ions

\begin{tabular}{|c|c|c|c|c|c|c|c|c|}
\hline \multicolumn{2}{|c|}{ angles } & \multicolumn{2}{|c|}{$\mathrm{N} 4 \cdots \mathrm{Fe} \cdots \mathrm{N} 3$} & \multicolumn{2}{|l|}{$\mathrm{N} 7 \cdots \mathrm{Zn} \cdots \mathrm{N} 11$} & $\mathrm{~N} 12 \cdots \mathrm{Zn} \cdots \mathrm{N} 4$ & \multicolumn{2}{|c|}{$\mathrm{N} 8 \cdots \mathrm{Zn} \cdots \mathrm{N} 3$} \\
\hline \multirow{2}{*}{\multicolumn{2}{|c|}{$\begin{array}{l}{\left[\mathrm{M}(\mathrm{L} 1)_{3}\right]\left(\mathrm{BF}_{4}\right)_{2}} \\
{\left[\mathrm{M}(\mathrm{L1})_{3}\right]\left(\mathrm{ClO}_{4}\right)_{2}}\end{array}$}} & \multicolumn{2}{|c|}{$173.24(8)$} & \multicolumn{2}{|l|}{$166.79(6)$} & $161.50(6)$ & \multicolumn{2}{|c|}{$172.99(6)$} \\
\hline & & \multicolumn{2}{|c|}{$173.34(8)$} & $167.19(7)$ & \multicolumn{2}{|r|}{$161.35(7)$} & \multicolumn{2}{|c|}{$173.24(7)$} \\
\hline bond lengths & $\mathrm{Fe} \cdots \mathrm{N} 3$ & $\mathrm{Fe} \cdots \mathrm{N} 4$ & $\mathrm{Zn} \cdots \mathrm{N} 7$ & $\mathrm{Zn} \cdots \mathrm{N} 11$ & $\mathrm{Zn} \cdots \mathrm{N} 12$ & $\mathrm{Zn} \cdots \mathrm{N} 4$ & $\mathrm{Zn} \cdots \mathrm{N} 3$ & $\mathrm{Zn} \cdots \mathrm{N} 8$ \\
\hline$\left[\mathrm{M}(\mathbf{L} \mathbf{1})_{3}\right]\left(\mathrm{BF}_{4}\right)_{2}$ & $1.9409(19)$ & $2.001(2)$ & $2.1476(16)$ & $2.1868(17)$ & $2.1619(17)$ & $2.1779(16)$ & $2.1480(17)$ & $2.1502(17)$ \\
\hline$\left[\mathrm{M}(\mathrm{L1})_{3}\right]\left(\mathrm{ClO}_{4}\right)_{2}$ & $1.9371(18)$ & $1.997(2)$ & $2.1545(17)$ & $2.1937(18)$ & $2.1589(17)$ & $2.1742(17)$ & $2.1468(18)$ & $2.1475(18)$ \\
\hline
\end{tabular}

benzylic $\mathrm{H} 36 \mathrm{~B}$ protons. A similar set of interactions takes place laterally to the assembly, between F3A and the triazole $\mathrm{H} 15$, as well as $\mathrm{F} 4 \mathrm{~A}$ and the benzylic proton $\mathrm{H} 22 \mathrm{~B}$ (Figure 4b).

All of these interactions observed in the tetrafluoroborate zinc(II) complex are conserved in the perchlorate analogue. Indeed, isostructural complexes are obtained between zinc(II) and $\mathbf{L} \mathbf{1}$ in both the tetrafluoroborate and perchlorate salts (Figure 4c). Hence, similarly to the iron(II) case, the same solidstate structures are obtained with zinc and symmetry-, size-, and polarization-related anions, $\mathrm{BF}_{4}{ }^{-}$and $\mathrm{ClO}_{4}{ }^{-}$, albeit in the mer isomer. The selection of the mer isomer for $\operatorname{zinc}(\mathrm{II})$ vs the $\mathrm{fac}$ isomer for iron(II) in this particular case of tetrahedral anions may be approached by qualitatively analyzing the thermodynamics of assembly, as well as the structural requirements for each metal ion. As apparent in Figure 4a, a "clamp-like" dimerization allows for the expression of multiple weak interactions along one surface, acting cooperatively, ${ }^{36-39}$ and forming, in the crystal, a collection of more individualized dimers. This is different from the largely integrated network of interconnected dimerization boxes expressed by the fac iron(II) isomer, where the interaction sites are dispersed in three dimensions, limiting cooperativity and decreasing entropy. From the anion's perspective, similar hydrogen-bonding interactions are expressed in the "dimerization pocket" (triazole $\mathrm{CH} \cdots \mathrm{F}$, and pyridine $\mathrm{H} \cdots \mathrm{F}$ interactions); hence, these tetrahedral anions are compatible with both isomers, although their location is better defined in the $f a c$ assembly. There may therefore be an overall bias toward the overall mer assembly in the solid state, however, at a cost. Indeed, the "clamp-like" dimerization requires bringing a set of three phenyl rings together as a capping unit, while preserving the $\pi-\pi$ stacking of two diads. Although such an arrangement is assisted by the very weak hydrogen bond between nitrogen atom N6 of axial triazoles with the "para" hydrogen atom on the diad pyridines, drawing these three benzyl units together while allowing diad stacking imposes significant distortions on the octahedral ion geometry, considering the limited flexibility of the benzylic hinge. This is apparent from the bond angles across the metal ions (Figure 5 and Table 3). Compared to the

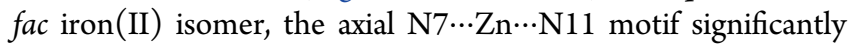
deviates from linearity; the triazole nitrogen atoms are pushed away from the dimer interface (Figure 5c, Figure 4b). This allows for the opening of the clamp, and the adjustment of the phenyl ring orientations to maximize aromatic interactions. These geometrical adjustments are facilitated by the geometric flexibility of the $\mathrm{d}^{10}$ zinc(II) ion, compared to the more rigid $\mathrm{d}^{6}$ iron(II) ion, as well as by the longer ion-nitrogen distances in the zinc compared to the iron complex. Both increased flexibility and longer interatomic distances around zinc(II) allow the expression of 
the mer isomer whose "clamp-like" self-assembly affords a more extensive set of interactions within one dimer.

In order to test the hypothesis according to which the geometrical flexibility of the metal ion plays a significant role in isomer selection, crystallization with a $\mathrm{d}^{8}$ metal ion such as nickel(II), which is able to adopt various geometries, ${ }^{40}$ was attempted in the presence of tetrahedral anions prone to fac crystallization with iron(II) and mer crystallization with zinc(II). Nickel(II) perchlorate was therefore mixed with $\mathbf{L} \mathbf{1}$ in a 1:3 ratio and crystallized by vapor diffusion of diethyl ether into a solution in acetonitrile. The resulting single crystals show the formation of the $\operatorname{mer}\left[\mathrm{Ni}(\mathbf{L 1})_{3}\right]\left(\mathrm{ClO}_{4}\right)_{2}$ isomer, essentially isostructural to the mer $\left[\mathrm{Zn}(\mathbf{L 1})_{3}\right]\left(\mathrm{ClO}_{4}\right)_{2}$ complex (Figure 6a; Table 4). Although

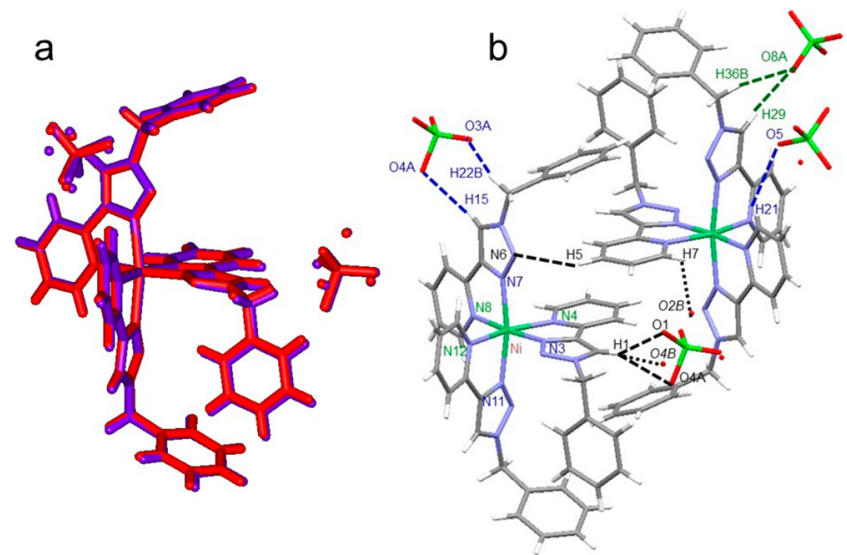

Figure 6. Solid-state structure of $\left[\mathrm{Ni}(\mathrm{L1})_{3}\right]\left(\mathrm{ClO}_{4}\right)_{2}$. (a) Overlay of $\left[\mathrm{Ni}(\mathbf{L 1})_{3}\right]\left(\mathrm{ClO}_{4}\right)_{2}$ (red) and $\left[\mathrm{Zn}(\mathbf{L} \mathbf{1})_{3}\right]\left(\mathrm{ClO}_{4}\right)_{2}$ (purple) solid-state structures (anions and hydrogen atoms are omitted for clarity). (b) Self-assembled "clamp" of enantiomers of $\left[\mathrm{Ni}(\mathrm{L1})_{3}\right]\left(\mathrm{ClO}_{4}\right)_{2}$, with $\mathrm{H}$-bonding to the $\mathrm{ClO}_{4}$ anion (dashed lines). Selected angles (deg): $\mathrm{N} 7 \cdots \mathrm{Ni} \cdots \mathrm{N} 11: \quad 169.60(9), \mathrm{N} 12 \cdots \mathrm{Ni} \cdots \mathrm{N} 4: \quad 165.40(8), \quad \mathrm{N} 8 \cdots \mathrm{Ni} \cdots \mathrm{N} 3$ :

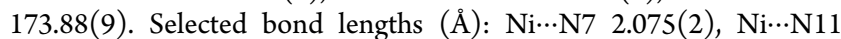

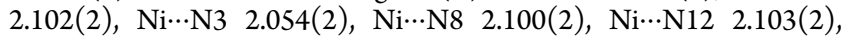
$\mathrm{Ni} \cdots \mathrm{N} 42.121(2)$. The labels for $\mathrm{N}$ from pyridines are color-coded in green, and the triazole nitrogen labels appear in blue.

bearing a non-benzylic triazole substituent, a bis-orthoisopropylphenyl-derived triazolylpyridine ligand has also been reported to crystallize as a mer tetrafluoroborate mononuclear nickel(II) complex. ${ }^{13}$ In the dinuclear context of a helicate, however, $f a c$ nickel(II) isomers are observed due to the presence of bridging spacers within the ligand, which enforces that all the triazole substituents be gathered together in order to allow the cooperative binding of the second nickel ion (Figure 1b).,18

Although the extent of distortion is not as extensive for the nickel(II) complex as it is in its zinc(II) counterpart (see angles listed in Figure 6 caption), it is sufficient to provide enough flexibility to allow the expression of the clamped mer structure, similar to that of the zinc complex. Therefore, flexibility around the metal ion is indeed a key parameter in the solid-state selection of the mer vs fac isomers of octahedral complexes derived from the N1-benzyl-triazolylpyridine ligand. ${ }^{43}$

In the complexes described above, the counterion parameter was kept constant, pertaining to the tetrahedral family, with $\delta$ - fluoride or $\delta$ - oxygen peripheral atoms. Due to their significant interactions with the organic fragment, and to the relevance of their symmetry to crystallization outcomes, the actual nature of the counteranions likely also contributes to fac vs mer selection. Therefore, an anion of lower symmetry such as a triflate was tested in the crystallization of $\left[\mathrm{Zn}(\mathbf{L 1})_{3}\right]^{2+}$ and $\left[\mathrm{Fe}(\mathbf{L 1})_{3}\right]^{2+}$ complexes, induced by the same conditions (diethyl ether diffusion into an acetonitrile solution of the complex). Not surprisingly, $\left[\mathrm{Zn}(\mathrm{Ll})_{3}\right](\mathrm{TfO})_{2}$ crystallizes as a mer complex, not unlike the structure observed for $\left[\mathrm{Zn}(\mathbf{L 1})_{3}\right]\left(\mathrm{ClO}_{4}\right)_{2}$ and $\left[\mathrm{Zn}(\mathbf{L 1})_{3}\right]$ $\left(\mathrm{BF}_{4}\right)_{2}$ (see Figure $7 \mathrm{a}$ for molecular complex overlay between the

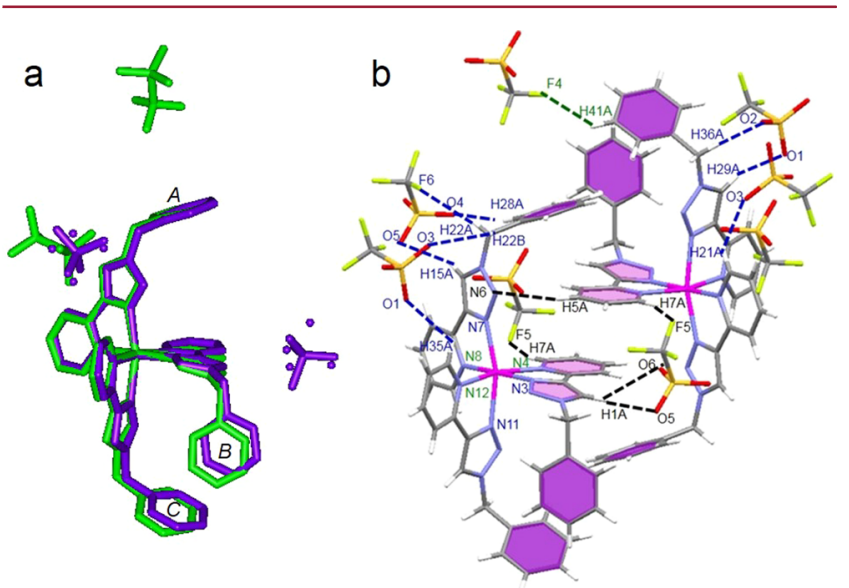

Figure 7. Solid-state structures of $\left[\mathrm{Zn}(\mathbf{L 1})_{3}\right]\left(\mathrm{F}_{3} \mathrm{C}-\mathrm{SO}_{3}\right)_{2}$. (a) Overlay of $\left[\mathrm{Zn}(\mathbf{L} \mathbf{1})_{3}\right]\left(\mathrm{F}_{3} \mathrm{C}-\mathrm{SO}_{3}\right)_{2}$ (green) and $\left[\mathrm{Zn}(\mathbf{L 1})_{3}\right]\left(\mathrm{ClO}_{4}\right)_{2}$ (purple) solidstate structures (anions and hydrogen atoms are omitted for clarity). (b) Self-assembled "clamp" $\left[\mathrm{Zn}(\mathbf{L} \mathbf{1})_{3}\right]\left(\mathrm{F}_{3} \mathrm{C}-\mathrm{SO}_{3}\right)_{2}$, with H-bonding to

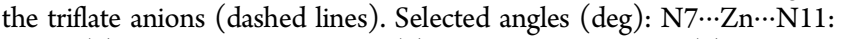

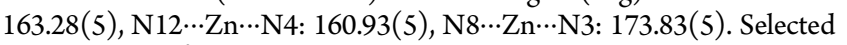

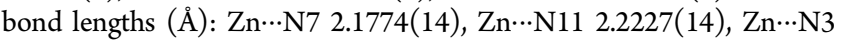

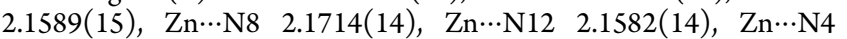
2.1631(14). The labels for $\mathrm{N}$ from pyridines are color-coded in green, and the triazole nitrogen labels appear in blue.

triflate and perchlorate complexes), forming a clamp-like dimer similar to the ones described above (Figure $7 \mathrm{~b}$ ). Most of the anion-to-ligand hydrogen-bonding interactions now involve the more densely charged triflate oxygen atoms, although its more weakly polarized fluorine substituents are still marginally engaged in some hydrogen-bonding in places. For instance, the head-to-tail dimerization of the diad is, here again, assisted

Table 4. Distances and Angles Involved in Hydrogen-Bonding within Self-Assembled $\left[\mathrm{Ni}(\mathrm{L1})_{3}\right]\left(\mathrm{ClO}_{4}\right)_{2}$

\begin{tabular}{|c|c|c|c|c|c|}
\hline & $\mathrm{H} 1^{b} \cdots \mathrm{O} 1$ & $\mathrm{H} 1^{b} \cdots \mathrm{O} 4 \mathrm{~A}$ & $\mathrm{H} 1^{b} \cdots \mathrm{O} 4 \mathrm{~B}$ & $\mathrm{H} 7^{b} \cdots \mathrm{O} 2 \mathrm{~B}$ & $\mathrm{H}^{b}{ }^{b} \cdots \mathrm{N} 6$ \\
\hline $\mathrm{H} \cdots \mathrm{A}$ distance $(\AA)^{a}$ & 2.46 & 2.61 & 2.69 & 2.71 & 3.46 \\
\hline $\mathrm{D} \cdots \mathrm{A}$ distance $(\AA)$ & $3.347(4)$ & $3.400(5)$ & $3.36(1)$ & $3.32(1)$ & $3.463(4)$ \\
\hline \multirow{2}{*}{$\mathrm{D}-\mathrm{H} \cdots \mathrm{A}$ angle $(\mathrm{deg})^{a}$} & 154.8 & 141.3 & 127.4 & 122.9 & 130.7 \\
\hline & $\mathrm{H} 36 \mathrm{~B}^{c} \cdots \mathrm{O} 8 \mathrm{~A}$ & $\mathrm{H} 29^{b} \cdots \mathrm{O} 8 \mathrm{~A}$ & $\mathrm{H} 15^{b} \cdots \mathrm{O} 4 \mathrm{~A}$ & $\mathrm{H} 22 \mathrm{~B}^{c} \cdots \mathrm{O} 3 \mathrm{~A}$ & \\
\hline $\mathrm{H} \cdots \mathrm{A}$ distance $(\AA)^{a}$ & 3.41 & 3.13 & 3.25 & 3.23 & \\
\hline $\mathrm{D} \cdots \mathrm{A}$ distance $(\AA)$ & $3.413(5)$ & $3.133(5)$ & $3.249(5)$ & $3.225(6)$ & \\
\hline $\mathrm{D}-\mathrm{H} \cdots \mathrm{A}$ angle $(\mathrm{deg})^{a}$ & 137.0 & 129.0 & 157.6 & 136.1 & \\
\hline
\end{tabular}

${ }^{a} \mathrm{H}$ atoms fixed at idealized positions. ${ }^{b} \mathrm{D}-\mathrm{H}$ distance set to $0.95 \AA$ on $\mathrm{sp}^{2}$ carbon ${ }^{c} \mathrm{D}-\mathrm{H}$ distance set to $0.99 \AA$ on $\mathrm{sp}^{3}$ carbon. 
Table 5. Distances and Angles Involved in Hydrogen-Bonding within Self-Assembled $\left[\mathrm{Zn}(\mathrm{L1})_{3}\right]\left(\mathrm{F}_{3} \mathrm{C}-\mathrm{SO}_{3}\right)_{2}$

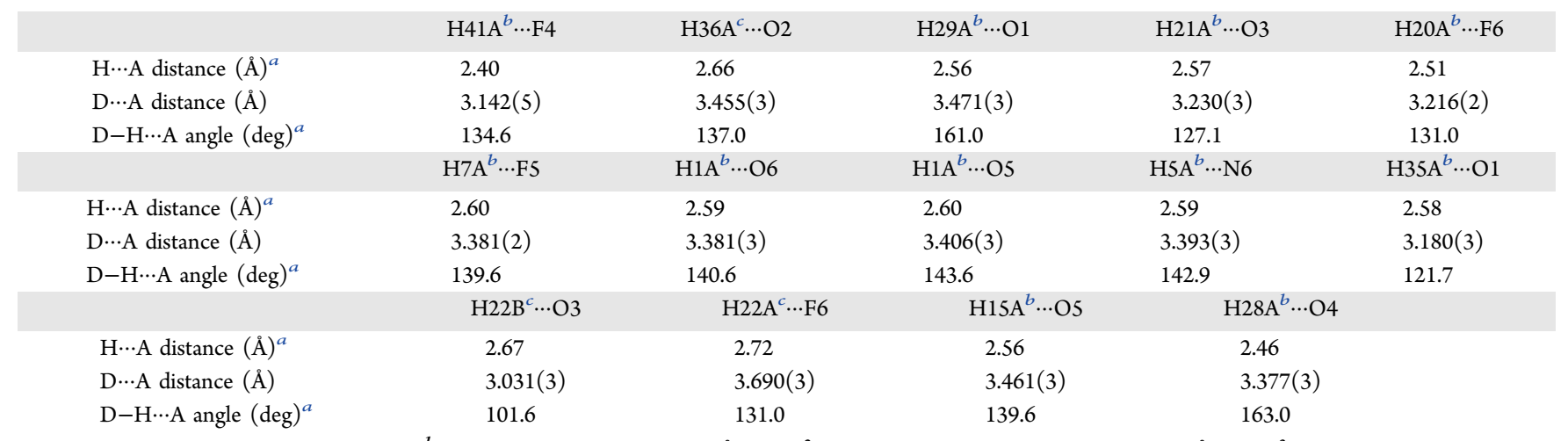

${ }^{a} \mathrm{H}$ atoms fixed at idealized positions. ${ }^{b} \mathrm{D}-\mathrm{H}$ distance set to $0.95 \AA$ on $\mathrm{sp}^{2}$ carbon ${ }^{c} \mathrm{D}-\mathrm{H}$ distance set to $0.99 \AA$ on $\mathrm{sp}^{3}$ carbon.

by hydrogen-bonding of the weakly acidic triazole hydrogen $\mathrm{H} 1 \mathrm{~A}$ to two triflate oxygen atoms (O5 and O6, bottom right of Figure $7 \mathrm{~b}$ ), while $\mathrm{H} 7 \mathrm{~A}$ belonging to the pyridine of the stacked diad enjoys a contact with the triflate's F5 atom, rather than interacting with a disordered anion position, as in the $\mathrm{BF}_{4}$ and $\mathrm{ClO}_{4}$ salts. Because the more elongated triflate anion now bridges the two stacked diads, the triazole ring in each diad is pushed out of chelating plane (see "horizontal" green triazole pushed down, away from the stacked diad, Figure $7 \mathrm{a} ; \mathrm{N} 3 \cdots \mathrm{C} 2 \cdots$ $\mathrm{C} 3 \cdots \mathrm{N} 4$ torsion angle of $\left.8.2(2)^{\circ}\right)$, whereas it was pulled "up" toward the stacked diad by the more compact tetrafluoroborate and perchlorate anions bridging the triazole of one diad and the pyridine of the other (see $\mathrm{H} 1 / \mathrm{F} 1, \mathrm{~F} 3 \mathrm{~A}$, and F3B, as well as $\mathrm{H} 7$ / F2B in Figure 4), resulting in a chelate twist in the other direction $\left(\mathrm{N} 3 \cdots \mathrm{C} 2 \cdots \mathrm{C} 3 \cdots \mathrm{N} 4\right.$ torsion angles of $-8.2(3)^{\circ}$ and $-8.4(3)^{\circ}$ for the perchlorate and tetrafluoroborate salts, respectively). This change in triazole orientation leads to a significant displacement of its connected benzyl group (ring B, Figure 7a), and, consequently, of the phenyl ring $C$ which it interacts with in an edge-to-face manner (Figure 7a). The other interactions are fairly conserved and unremarkable, compared to the perchlorate and tetrafluoroborate salts; the two hydrogen atoms from the triazoles that are not involved in $\pi-\pi$ stacking are engaged in weak hydrogen-bonding with oxygen atoms from triflate anions (H15A/O5, Figure 7b, left, and H29A/O1, Figure $7 \mathrm{~b}$, right; Table 5), along the vertical edges of the dimer, as they are in the tetrafluoroborate and perchlorate structures.

Most importantly, $\left[\mathrm{Fe}(\mathbf{L} 1)_{3}\right](\mathrm{TfO})_{2}$ also crystallizes as a mer complex (Figure 8a), indicative of the critical role of the counteranion in the fac vs mer isomer selection for the iron(II) complexes. However, the solid-state structure of this iron(II) mer complex is significantly different from that of the zinc(II) and nickel(II) mer complexes described above. First, the structure displays an increased extent of disorder in the position of the cationic unit (ring B, Figure 8a) and of one triflate anion, and incorporates solvent molecules of diethyl ether, suggesting looser packing interactions of the complexes in the solid state. Second, as anticipated based on the discussion above, the more rigid iron(II) center adopts a much closer pseudo-octahedral geometry than the more flexible zinc(II) and nickel(II) structures, as evidenced by the trans $\mathrm{N}_{x} \cdots \mathrm{Fe} \cdots \mathrm{N}_{y}$ angles $\left(\mathrm{N}_{x}, \mathrm{~N}_{y}=\right.$ $\mathrm{N} 7, \mathrm{~N} 11$; N12, N4; and N8, N3) that range from $171^{\circ}$ to $175.5^{\circ}$ for the iron(II) complex, similar to the ones observed in the iron(II) fac complex above. Figure $8 \mathrm{~b}$ displays an overlay of the iron (orange) and zinc (green) triflate complexes, highlighting the significant difference in the extent of distortion between the zinc and iron triflate complexes.
As a result of the more rigid geometry around the iron(II) center, and probably of shorter nitrogen-to-ion distances, the opening of the clamp observed in the mer complexes of zinc(II) and nickel(II) is absent from the mer iron(II) complex, and consequently, the $\pi-\pi$ stacking of the N3,N4-containing triazolylpyridine diads is impeded (see Figure 8a for nitrogen labeling). As a matter of fact, none of chelate 1 (incorporating N3 and N4), chelate 2 (incorporating N11 and N12), and chelate 3 (incorporating N7 and N8) is involved in diad $\pi-\pi$ stacking. Figure $8 \mathrm{c}-\mathrm{e}$ illustrates the solid-state self-assembly around chelates 1,2 , and 3, respectively. Rather than being involved in diad $\pi-\pi$ stacking as it is in the other mer complexes described above, chelate 1 crystallized with partial insertion of ring $\mathrm{C}$ (pink in Figure 8c) of a neighboring complex above the triazole ring (see N3,N4-chelate 1 of "complex 1" partially stacked with ring C of "complex 2" in Figure 8c). Such interaction is reinforced through edge-to-face interactions (represented in purple in Figure 8c, top) of ring B of "complex 2" with ring A of "complex 1". Similarly, rings B and C of "complex 1" interact through edge-to-face interactions with the pyridine of N7,N8chelate 3 from "complex 3 " on the other side of the diad (Figure $8 \mathrm{c}$, bottom). Chelate 1 is also stabilized via weak hydrogenbonding of its triazole and pyridine hydrogen atoms with triflate oxygen atoms (see H1/O55 and H5/O65 in Figure 8c). Finally, the upper face of the chelate 1 diad benefits not only from partial stacking with ring $\mathrm{C}$ but also from contacts with the hydrophobic fluorine atoms from the hydrogen-bonded triflates. These two types of contacts essentially replace the $\pi-\pi$ stacking expressed in the more flexible mer zinc and nickel dimers. Not surprisingly, chelate 2 mostly interacts with its surrounding through the expected weak hydrogen-bonding of its $\mathrm{CH}$ bonds with triflate oxygen (H29/O67, H32/O65, H35/O67, Figure 8d) and fluorine (F55/H34, Figure $8 \mathrm{~d}$ ) atoms. Chelate 3, however, is lined by a molecule of diethyl ether on one side (see chelate 3 highlighted in light pink at the bottom left of Figure 8e, and lined with a nearby $\mathrm{Et}_{2} \mathrm{O}$ molecule). The combination of ring $\mathrm{C}$ and chelate 2, which obstruct the other face of chelate 3 , impedes any additional stacking interaction (Figure 8e, middle). The edge of chelate 3 however expresses the expected triazole hydrogen/ triflate oxygen and pyridine hydrogen/triflate oxygen weak hydrogen-bonding observed with the other ligands (see H15/ O56 and O57, and H21/O55 in Figure 8e, middle), complemented by an edge-to-face interaction with ring $\mathrm{B}$ from a neighboring complex (Figure 8e).

Overall, the present analysis of the solid-state structure and self-assembly of N1-benzyl-triazolylpyridine-derived pseudooctahedral complexes with labile metal ions points to the 


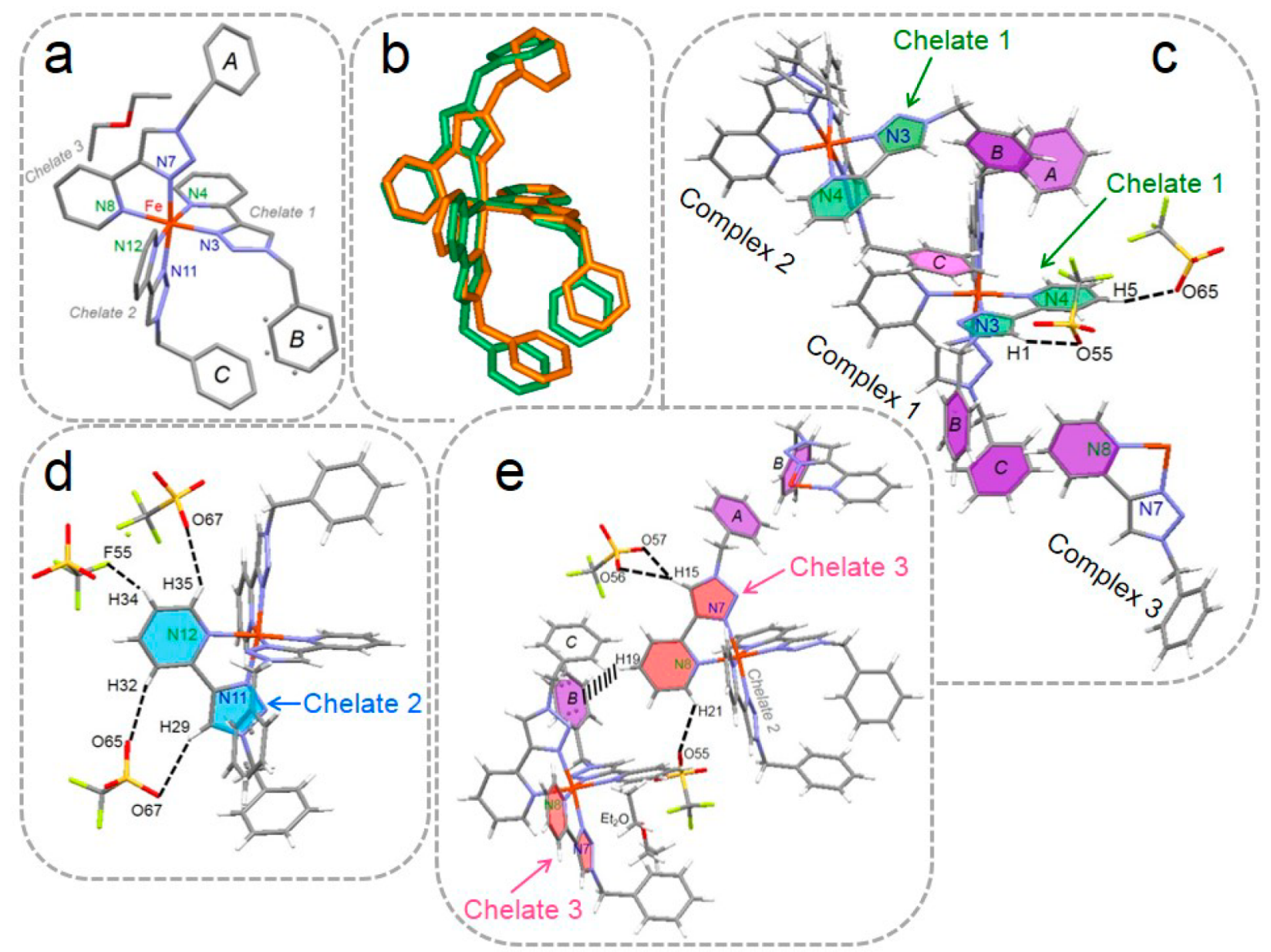

Figure 8. Solid-state structures of $\left[\mathrm{Fe}(\mathrm{L1})_{3}\right]\left(\mathrm{F}_{3} \mathrm{C}-\mathrm{SO}_{3}\right)_{2}$. (a) View of the monomer (the labels for $\mathrm{N}$ from pyridines are color-coded in green, and

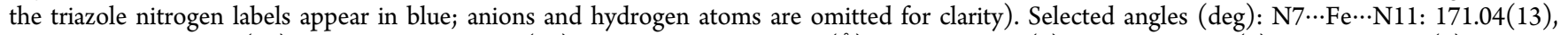
$\mathrm{N} 12 \cdots \mathrm{Fe} \cdots \mathrm{N} 4: 172.38(12), \mathrm{N} 8 \cdots \mathrm{Fe} \cdots \mathrm{N} 3:$ 175.54(12). Selected bond lengths $(\AA)$ : $\mathrm{Fe} \cdots \mathrm{N} 7$ 1.938(2), $\mathrm{Fe} \cdots \mathrm{N} 11$ 1.953(2), $\mathrm{Fe} \cdots \mathrm{N} 31.931(3), \mathrm{Fe} \cdots \mathrm{N} 8$ 2.000(3), $\mathrm{Fe} \cdots \mathrm{N} 12$ 1.987(3), Fe $\cdots \mathrm{N} 42.014(3)$. (b) Overlay of $\left[\mathrm{Fe}(\mathbf{L 1})_{3}\right]\left(\mathrm{F}_{3} \mathrm{C}-\mathrm{SO}_{3}\right)_{2}$ (orange) and $\left[\mathrm{Zn}(\mathbf{L} 1)_{3}\right]\left(\mathrm{F}_{3} \mathrm{C}-\mathrm{SO}_{3}\right)_{2}($ green) solid-state structures (anions, hydrogen atoms, and solvent are omitted for clarity). Self-assembly of $\left[\mathrm{Fe}(\mathbf{L} \mathbf{1})_{3}\right]\left(\mathrm{F}_{3} \mathrm{C}-\mathrm{SO}_{3}\right)_{2}$ units around chelate 1 (c), chelate 2 (d), and chelate 3 (e). In (c) and (e), irrelevant portions of a few complexes, as well as some incorporated solvent molecules, have been deleted for

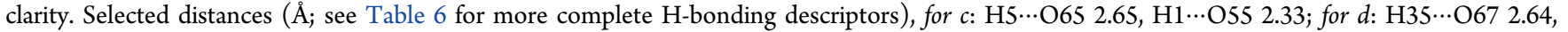

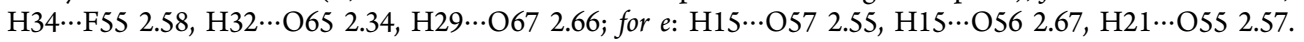

Table 6. Distances and Angles Involved in Hydrogen-Bonding within Self-Assembled $\left[\mathrm{Fe}(\mathrm{L1})_{3}\right]\left(\mathrm{F}_{3} \mathrm{C}-\mathrm{SO}_{3}\right)_{2}$

\begin{tabular}{|c|c|c|c|c|c|}
\hline & $\mathrm{H} 5 \cdots \mathrm{O} 65$ & $\mathrm{H} 1 \cdots \mathrm{O} 55$ & $\mathrm{H} 35 \cdots \mathrm{O} 67$ & 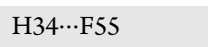 & $\mathrm{H} 32 \cdots \mathrm{O} 65$ \\
\hline $\mathrm{H} \cdots \mathrm{A}$ distance $(\AA)^{a}$ & 2.65 & 2.33 & 2.64 & 2.58 & 2.34 \\
\hline $\mathrm{D} \cdots \mathrm{A}$ distance $(\AA)$ & $3.534(5)$ & $3.254(5)$ & $3.401(4)$ & $3.434(5)$ & $3.281(5)$ \\
\hline \multirow[t]{2}{*}{$\mathrm{D}-\mathrm{H} \cdots \mathrm{A}$ angle $(\mathrm{deg})^{a}$} & 155.9 & 163.2 & 137.5 & 149.6 & 169.7 \\
\hline & $\mathrm{H} 29 \cdots \mathrm{O} 67$ & $\mathrm{H} 15 \cdots \mathrm{O} 57$ & H15 $\cdots \mathrm{O} 56$ & $\mathrm{H} 21 \cdots \mathrm{O} 55$ & \\
\hline $\mathrm{H} \cdots \mathrm{A}$ distance $(\AA)^{a}$ & 2.66 & 2.55 & 2.67 & 2.57 & \\
\hline $\mathrm{D} \cdots \mathrm{A}$ distance $(\AA)$ & $3.517(5)$ & $3.332(5)$ & $3.590(5)$ & $3.187(5)$ & \\
\hline $\mathrm{D}-\mathrm{H} \cdots \mathrm{A}$ angle $(\mathrm{deg})^{a}$ & 150.8 & 139.5 & 162.3 & 123.1 & \\
\hline
\end{tabular}

following key features in the fac vs mer isomer solid-state selection:

(i) The geometrically flexible $\mathrm{d}^{8}$ and $\mathrm{d}^{10}$ labile metal ions facilitate crystallization of the mer isomer into a "clamp"-like structure where many interactions including hydrogenbonding, face-to-face, and edge-to-face aromatic contacts presumably act cooperatively to generate a somewhat isolated dimer. The "clamp"-like structure requires significant distortion of the triazole-ion-triazole and pyridine-ion-pyridine bond angles. $A \mathrm{~d}^{6}$ cation such as low-spin iron(II), which would suffer from the costly destabilization of its $\mathrm{T}_{2 \mathrm{~g}}$ bonding $\mathrm{d}$ electrons, does not accommodate such a required distorted conformation well, and crystallizes as a fac isomer, provided the anion is of appropriate shape (such as small and tetrahedral). A tight $3 \mathrm{D}$ network of $\mathrm{fac}$ isomers is then created through the formation of "dimerization boxes" along each of the three ligands of each mononuclear unit.

(ii) However, in the case of iron(II), the counteranion plays a determining role, as a more elongated and symmetrically 
distinct triflate anion drives the selection to a mer isomer, the self-assembly of which differs from the mer isomers of more flexible metal ions.

The analysis of the decisive parameters listed above strictly only applies to the N1-benzyl-triazolylpyridine ligand, as the phenyl ring and benzylic hydrogen atoms actively participate in building the set of interactions driving the selection. As such, this study may appear fairly restricted in its scope. However, its value may become more apparent when considering the following features: (i) the benzyl-triazole unit is fairly popular due to its ease of synthesis (benzylazide is commercially available or, alternatively, very simply prepared by a facile $S_{N} 2$ in situ reaction), its convenient spectroscopic signature, and crystallization propensity; (ii) the counteranion control of $\mathrm{fac} / \mathrm{mer}$ selection is particularly attractive for iron(II) complexes, as it has been shown that the triazolyl-pyridine ligand strength allows access to spin crossover behavior. Although the mononuclear complexes have all been observed as low-spin species in our hands, minor modifications on the pyridine unit may easily be implemented to decrease the diad's field strength. Since the hydrogen on position 5 on the pyridine ("meta" to nitrogen) does not seem to bear essential interactions in the solid-state assembly, it is an ideal position for ligand-field tuning. Providing similar crystallization rules still holds in such modified diads, controlling the mer/fac selection based on the nature of the counterion would be of great value, as the $\mathrm{Fe}-\mathrm{Fe}$ distances, as well the tightness and therefore collective behavior of the solidstate assembly, strongly differ in these two isomers, which will likely influence spin crossover behavior. ${ }^{41}$

\section{ASSOCIATED CONTENT}

\section{S Supporting Information}

The Supporting Information is available free of charge on the ACS Publications website at DOI: 10.1021/acs.cgd.7b01495.

(i) Details of solution-state analysis, (ii) longer range $\left[\mathrm{Zn}(\mathbf{L 1})_{3}\right]\left(\mathrm{BF}_{4}\right)_{2}$ self-assembly analysis, (iii) X-ray data for $\left[\mathrm{Fe}(\mathbf{L 1})_{3}\right]\left(\mathrm{BF}_{4}\right)_{2}(\mathrm{CCDC} 1577992),\left[\mathrm{Fe}(\mathbf{L 1})_{3}\right]\left(\mathrm{ClO}_{4}\right)_{2}$ (CCDC 1577996), $\left[\mathrm{Zn}(\mathbf{L 1})_{3}\right]\left(\mathrm{BF}_{4}\right)_{2}(\mathrm{CCDC} 1577997)$, $\left[\mathrm{Zn}(\mathbf{L 1})_{3}\right]\left(\mathrm{ClO}_{4}\right)_{2}(\mathrm{CCDC} 1577998),\left[\mathrm{Ni}(\mathbf{L 1})_{3}\right]\left(\mathrm{ClO}_{4}\right)_{2}$ (CCDC 1577999), $\left[\mathrm{Zn}(\mathbf{L 1})_{3}\right]\left(\mathrm{F}_{3} \mathrm{C}-\mathrm{SO}_{3}\right)_{2} \quad(\mathrm{CCDC}$ 808350), and $\left[\mathrm{Fe}(\mathrm{Ll})_{3}\right]\left(\mathrm{F}_{3} \mathrm{C}-\mathrm{SO}_{3}\right)_{2}(\mathrm{CCDC} 1578000)$ (PDF)

\section{Accession Codes}

CCDC 1578000, 1577992, 1577996-1577999, and 808350 contain the supplementary crystallographic data for this paper. These data can be obtained free of charge via www.ccdc.cam.ac.uk/data_request/cif, or by emailing data_request@ccdc. cam.ac.uk, or by contacting The Cambridge Crystallographic Data Centre, 12 Union Road, Cambridge CB2 1EZ, UK; fax: +441223336033.

\section{AUTHOR INFORMATION}

\section{Corresponding Author}

*E-mail: anne.petitjean@chem.queensu.ca.

\section{ORCID $\odot$}

Anne Petitjean: 0000-0003-2085-1884

\section{Author Contributions}

The manuscript was written through contributions of all authors. All authors have given approval to the final version of the manuscript.

\section{Funding}

Funding from the Natural Sciences and Engineering Research Council (NSERC-DG; grant number 315311-2013) and Queen's University is acknowledged.

\section{Notes}

The authors declare no competing financial interest.

\section{REFERENCES}

(1) Struthers, H.; Mindt, T. L.; Schibli, R. Dalton Trans. 2010, 39, 675-696.

(2) Aromí, G.; Barrios, L. A.; Roubeau, O.; Gamez, P. Coord. Chem. Rev. 2011, 255, 485-546.

(3) Crowley, J. D.; McMorran, D. A. Top. Heterocycl. Chem. 2012, 28, $31-84$.

(4) Wu, N.; Melan, C. F. C.; Stevenson, K. A.; Fleischel, O.; Guo, H.; Habib, F.; Holmberg, R. J.; Murugesu, M.; Mosey, N. J.; Nierengarten, H.; Petitjean, A. Dalton Trans. 2015, 44, 14991-15005.

(5) Akhuli, B.; Cera, L.; Jana, B.; Saha, S.; Schalley, C. A.; Ghosh, P. Inorg. Chem. 2015, 54, 4231-4242.

(6) Jana, B.; Cera, L.; Akhuli, B.; Naskar, S.; Schalley, C. A.; Ghosh, P. Inorg. Chem. 2017, 56, 12505-12513.

(7) Happ, B.; Escudero, D.; Hager, M. D.; Friebe, C.; Winter, A.; Görls, H.; Altuntas, E.; González, L.; Schubert, U. S. J. Org. Chem. 2010, 75, 4025-4038.

(8) Romero, T.; Orenes, R. A.; Espinosa, A.; Tárraga, A.; Molina, P. Inorg. Chem. 2011, 50, 8214-8224.

(9) Bertrand, H. C.; Clède, S.; Guillot, R.; Lambert, F.; Policar, C. Inorg. Chem. 2014, 53, 6204-6223.

(10) Kerr, E.; Doeven, E. H.; Barbante, G. J.; Connell, T. U.; Donnelly, P. S.; Wilson, D. J. D.; Ashton, T. D.; Pfeffer, F. M.; Francis, P. S. Chem. - Eur. J. 2015, 21, 14987-14995.

(11) Connell, T. U.; White, J. M.; Smith, T. A.; Donnelly, P. S. Inorg. Chem. 2016, 55, 2776-2790.

(12) Guha, P. M.; Phan, H.; Kinyon, J. S.; Brotherton, W. S.; Sreenath, K.; Simmons, J. T.; Wang, Z.; Clark, R. J.; Dalal, N. S.; Shatruk, M.; Zhu, L. Inorg. Chem. 2012, 51, 3465-3477.

(13) Schweinfurth, D.; Krzystek, J.; Schapiro, I.; Demeshko, S.; Klein, J.; Telser, J.; Ozarowski, A.; Su, C.-Y.; Meyer, F.; Atanasov, M.; Neese, F.; Sarkar, B. Inorg. Chem. 2013, 52, 6880-6892.

(14) Romero-Morcillo, T.; Valverde-Muñoz, F. J.; Piñeiro-López, L.; Muñoz, M. C.; Romero, T.; Molina, P.; Real, J. A. Dalton Trans. 2015, 44, 18911-18918.

(15) Fleischel, O.; Wu, N.; Petitjean, A. Chem. Commun. 2010, 46, 8454-8456.

(16) Lo, W. K. C.; Huff, G. S.; Cubanski, J. R.; Kennedy, A. D. W.; McAdam, C. J.; McMorran, D. A.; Gordon, K. C.; Crowley, J. D. Inorg. Chem. 2015, 54, 1572-1587.

(17) Suntrup, L.; Klenk, S.; Klein, J.; Sobottka, S.; Sarkar, B. Inorg. Chem. 2017, 56, 5771-5783.

(18) Stevenson, K. A.; Melan, C. F. C.; Fleischel, O.; Wang, R.; Petitjean, A. Cryst. Growth Des. 2012, 12, 5169-5173.

(19) Vellas, S. K.; Lewis, J. E. M.; Shankar, M.; Sagatova, A.; Tyndall, J. D. A.; Monk, B. C.; Fitchett, C. M.; Hanton, L. R.; Crowley, J. D. Molecules 2013, 18, 6383-6407.

(20) Pokharel, U. R.; Fronczek, F. R.; Maverick, A. W. Dalton Trans. 2013, 42, 14064-14067.

(21) Lewis, J. E. M.; Elliott, A. B. S.; McAdam, C. J.; Gordon, K. C.; Crowley, J. D. Chem. Sci. 2014, 5, 1833-1843.

(22) Pokharel, U. R.; Fronczek, F. R.; Maverick, A. W. Nat. Commun. 2014, 5, 5883-5888.

(23) Preston, D.; Tucker, R. A. J.; Garden, A. L.; Crowley, J. D. Inorg. Chem. 2016, 55, 8928-8934.

(24) Vasdev, R. A. S.; Preston, D.; Crowley, J. D. Dalton Trans. 2017, $46,2402-2414$

(25) Kumar, S. V.; Scottwell, S. Ø.; Waugh, E.; McAdam, C. J.; Hanton, L. R.; Brooks, H. J. L.; Crowley, J. D. Inorg. Chem. 2016, 55, 9767-9777. 
(26) Reiher, M.; Salomon, O.; Hess, B. A. Theor. Chem. Acc. 2001, $107,48-55$.

(27) Salomon, O.; Reiher, M.; Hess, B. A. J. Chem. Phys. 2002, 117, $4729-4737$.

(28) Hua, Y.; Flood, A. H. Chem. Soc. Rev. 2010, 39, 1262-1271.

(29) Zornik, D.; Meudtner, R. M.; El Malah, T.; Thiele, C. M.; Hecht, S. Chem. - Eur. J. 2011, 17, 1473-1484.

(30) You, L.-Y.; Chen, S.-G.; Zhao, X.; Liu, Y.; Lan, W.-X.; Zhang, Y.; Lu, H.-J.; Cao, C.-Y.; Li, Z.-T. Angew. Chem., Int. Ed. 2012, 51, 16571661.

(31) Yang, S.-T.; Liao, D.-J.; Chen, S.-J.; Hu, C.-H.; Wu, A.-T. Analyst 2012, 137, 1553-1555.

(32) Caricato, M.; Olmo, A.; Gargiulli, C.; Gattuso, G.; Pasini, D. Tetrahedron 2012, 68, 7861-7866.

(33) Lu, B.-Y.; Li, Z.-M.; Zhu, Y.-Y.; Zhao, X.; Li, Z.-T. Tetrahedron 2012, 68, 8857-8862.

(34) Rawson, J. M.; Donato, L.; Zysman-Colman, E. CrystEngComm 2014, 16, 8531-8536.

(35) Song, Z.; Mansbach, R. A.; He, H.; Shih, K.-C.; Baumgartner, R.; Zheng, N.; Ba, X.; Huang, Y.; Mani, D.; Liu, Y.; Lin, Y.; Nieh, M.-P.; Ferguson, A. L.; Yin, L.; Cheng, J. Nat. Commun. 2017, 8, 92-99.

(36) Williams, D. H.; Searle, M. S.; Groves, P.; Mackay, J. P.; Westwell, M. S.; Beauregard, D. A.; Cristofaro, M. F. Pure Appl. Chem. 1994, 66, 1975-1982.

(37) Williams, D. H.; Westwell, M. S. Chem. Biol. 1996, 3, 695-701.

(38) Inoue, Y.; Wada, T. Adv. Supramol. Chem. 1997, 4, 55-96.

(39) Fasting, C.; Schalley, C. A.; Weber, M.; Seitz, O.; Hecht, S.; Koksch, B.; Dernedde, J.; Graf, C.; Knapp, E.-W.; Haag, R. Angew. Chem., Int. Ed. 2012, 51, 10472-10498.

(40) Cotton, F. A.; Wilkinson, G. Advanced Inorganic Chemistry; John Wiley \& Sons, Inc.: New York, 1988; Chapter 18, pp 741-755.

(41) Konig, E.; Ritter, G.; Kulshreshtha, S. K. Chem. Rev. 1985, 85, 219-234.

(42) DFT calculations were performed at the B3LYP*/TZVP level of theory, which have been shown to accurately reproduce the ground states of iron(II) complexes, according to refs 26 and 27.

(43) The selection of the mer isomer was also observed in the solidstate structure of $\left[\mathrm{Ni}(\mathbf{L} \mathbf{1})_{3}\right]\left(\mathrm{BF}_{4}\right)_{2}$ (unpublished results). 